MagNetE workshop 2011

\title{
Repeat station data compared to a global geomagnetic field model
}

\author{
Monika Korte and Vincent Lesur
}

Helmholtz-Centre Potsdam, GFZ German Research Centre for Geosciences, Potsdam, Germany

\author{
Article history \\ Received October 4, 2011; accepted January 18, 2012. \\ Subject classification: \\ Geomagnetism, Global and regional models, Main geomagnetic field.
}

\begin{abstract}
Geomagnetic repeat station surveys with local variometers for improved data reductions have been carried out in Germany for about ten years. For nearly the same time interval the satellites Ørsted and CHAMP have provided a good magnetic field data coverage of the whole globe. Recent global field models based on these satellite data together with geomagnetic observatory data provide an improved description of the core field and secular variation. We use the latest version of the GFZ Reference Internal Magnetic Model to compare the magnetic field evolution predicted by that model between 2001 and 2010 to the independent repeat station data collected over the same time interval in Germany. Estimates of crustal bias at the repeat station locations are obtained as averages of the residuals, and the scatter or trend around each average provides information about influences in the data from field sources not (fully) described by the global model. We find that external magnetic field signal in the order of several $n T$, including long-term trends, remains both in processed annual mean and quiet night time repeat station data. We conclude that the geomagnetic core field secular variation in this area is described to high accuracy (better than $1 \mathrm{nT} / \mathrm{yr}$ ) by the global model. Weak long-term trends in the residuals between repeat station data and the model might indicate induced lithospheric anomalies, but more data are necessary for a robust analysis of such signals characterized by very unfavorable signal-to-noise ratio.
\end{abstract}

\section{Introduction}

Geomagnetic repeat station surveys are carried out in many countries for the purpose of regionally mapping the Earth's magnetic field components and their secular variation. A geomagnetic repeat station is a well-defined geographic location where magnetic field observations are carried out once a year to once every few years. Appropriate measurement procedures and data processing are applied to minimize the influence of the highly variable external magnetic field contributions originating in the ionosphere and the magnetosphere and their induced counterparts, and thus to obtain results that reflect the core and lithospheric field contributions [Newitt et al. 1996]. These efforts, however, are limited by the fact that observations at a repeat station cover a couple of days at best.

The practical benefit of magnetic repeat station data clearly lies in keeping a country independent from the availability of worldwide data and global main field models for mapping the geomagnetic field, particularly the declination for navigational purposes. The scientific value of repeat station data has sometimes been doubted, in particular for regions such as Europe, covered comparatively densely by continuously recording geomagnetic observatories. Newitt et al. [1996] have highlighted the importance of accuracy and have stated that "repeat station data must be at least good enough to improve the accuracy of SV [secular variation] models produced from observatory data alone. If they are not accurate enough to do this, then the effort expended on repeat measurements is wasted". Considering that the source of secular variation lies in the Earth's core and accepting the standard assumption of an insulating mantle, it might indeed seem that in central Europe with a spacing of less than 1000 $\mathrm{km}$ between magnetic observatories, additional repeat station measurements cannot provide any further information.

However, they can contribute a substantial amount of information about the crust and perhaps the upper mantle. Repeat station data from France and Germany have been used to create medium-scale vector magnetic anomaly maps [Thébault et al. 2006, Korte and Thébault 2007]. A longstanding question in geomagnetism is whether induction by the slowly changing main field in conductive structures in the lithosphere is a measurable part of what is observed as secular variation at and above the Earth's surface. Such signals of time-varying lithospheric anomalies would be useful e.g. to distinguish between remanent and induced sources of crustal magnetic anomalies [Lesur and Gubbins 2000, Jackson 2007] and provide information about the local or regional lithospheric susceptibility with implications for geological and tectonic studies. Moreover, it is important to separate any induced lithospheric time varying signal from true core field secular variation in high resolution spherical harmonic magnetic field models when they are used to study geodynamo processes [McLeod 1996, Hulot et al. 2009].

Earlier attempts to detect secular variation anomalies due to lithospheric induction focused Europe, where the 
highest density of geomagnetic ground observations exists [Mundt 1978, Mundt 1981, Mundt and Porstendorfer 1977, Mundt and Porstendorfer 1978, Spitta 1991, Podsklan et al. 1993]. Most of these studies suggest the existence of induced time-varying anomalies, but none of them is conclusive in terms of their exact dimension and origin. Investigations of only geomagnetic observatory data indicate significant induced magnetization components, but the distances between the observatories are too large to allow for inferences on crustal structure [Alldredge 1983, Lesur and Gubbins 2000, Macmillan and Thomson 2003, Verbanac et al. 2007]. Thébault et al. [2009] estimated rates of change of induced lithospheric anomalies based on a vertically integrated susceptibility grid of the Earth's crust [Hemant and Maus 2005] for anomalies of wavelengths between 440 and $2700 \mathrm{~km}$. They estimate values of up to $1.30 \mathrm{nT} / \mathrm{yr}$ in certain areas, but not exceeding 0.1 $\mathrm{nT} / \mathrm{yr}$ in western Europe. However, more localized anomalies which might give stronger small-scale signals might also exist.

In this study, we use the German high quality repeat station data collected between 2000 and 2010 within the European MagNetE program and compare those data to a recent global geomagnetic field model based on satellite and observatory data. We investigate and discuss differences seen in secular variation from the repeat stations and the global model and discuss different estimates of the lithospheric signal at the repeat stations. Finally, we draw conclusions about the influence of external fields in processed repeat station data and on their ability to provide information about remanent and induced contributions to lithospheric magnetic anomalies.

\section{Repeat station data}

Germany does not have a long history of true repeat station surveys with re-occupation intervals of five years or less. A repeat station network was defined in 1996, using a number of repeat stations that had existed for a few years in the former German Democratic Republic and a sub-set of documented ground vector survey stations which had been used around 1965 and 1982 in former West Germany. The network consists of two classes of stations: firstly, there are 12 high quality stations (first order stations) where a variometer is operated nearby the station for at least three days and including at least one night with very low magnetic activity. Secondly, our surveys include up to 36 of the former ground vector survey stations, surrounding the variometer stations. Absolute measurements are carried out at those stations while the variometer is running at the nearest first order station, in general no further than $150 \mathrm{~km}$ away. Experiences from the first use of the in situ variometer and problems with technical disturbances at some stations unfortunately required some changes in both repeat station and variometer networks over the years. In this study, we consider only first order stations where an in situ variometer was frequently operated and the highest possible accuracy can be expected, shown in Figure 1. Four geomagnetic observatories are constantly recording the geomagnetic field in Germany, these are Niemegk (NGK), Wingst (WNG) and Fürstenfeldbruck (FUR) with long time series and the more recently established Black Forest Observatory (BFO).

From 1999 to 2002 surveys were carried out covering half the network each year, using the standard absolute equipment of a DI-flux theodolite (Zeiss 010B with Bartington sensor) and an Overhauser magnetometer (Gem Systems GSM 19), and at the first order stations additionally a LEMI 008 fluxgate vector variometer. The annual mean results are reduced to the middle of the year in which the measurements were carried out, i.e. results exist for 1999.5/2000.5 and 2001.5/2002.5 [Korte and Fredow 2001]. In 2003, the MagNetE (Magnetic Network of Europe) initiative to standardize repeat station surveys all over Europe started [Korte and Mandea 2003]. The agreed recommendation was to carry out surveys on the complete networks in all countries bi-annually, starting in 2004. As a consequence the survey that had been started in 2003 in Germany was extended to as many stations as possible, yielding results for about $80 \%$ of the full network. From 2004 to 2010 bi-annual surveys of the whole network were carried out.

Repeat station survey results are commonly given as 'annual means', all reduced to the middle of a given year, in order to eliminate transient external field contributions and allow for mapping of the internal field components together with standard observatory annual means. This data reduction is done in two steps for our first order stations. First, a quiet night time value is obtained for each magnetic field component $C$ at station $x$ and the most quiet night while the variometer was recording at that station:

$C_{\mathrm{QN}}\left(x, t_{\mathrm{QN}}\right)=V C_{\mathrm{QN}}\left(x, t_{\mathrm{QN}}\right)+[C(x, t)-V C(x, t)]$

Here, $C(x, t)$ is the absolute component observation carried out at time $t$, and and $V C(x, t)$ are the variation recordings of component $C$ at the quiet night time $t_{\mathrm{QN}}$ and the time of the absolute measurement, $t$, respectively. $V C_{Q N}$ and consequently the resulting $C_{\mathrm{QN}}$ are taken as averages over a range of night time values, in general in the order of a few hours, when the magnetic $\mathrm{K}$ index at Niemegk observatory is lowest and the variation recordings visually appear best to reflect a nearly constant quiet internal field level. These quiet night time results for different days (nights) within the year are further reduced to common annual means centered on the middle of the year by

$$
C_{A M}\left(x, t_{A M}\right)=O C_{A M}\left(x, t_{A M}\right)+\left[C_{Q N}\left(x, t_{Q N}\right)-O C_{Q N}\left(O, t_{Q N}\right)\right] .
$$

Now, $O C_{A M}$ and $O C_{Q N}$ are the annual mean and equivalent quiet night time value at magnetic observatory $O$, in our case the Niemegk observatory (NGK). 


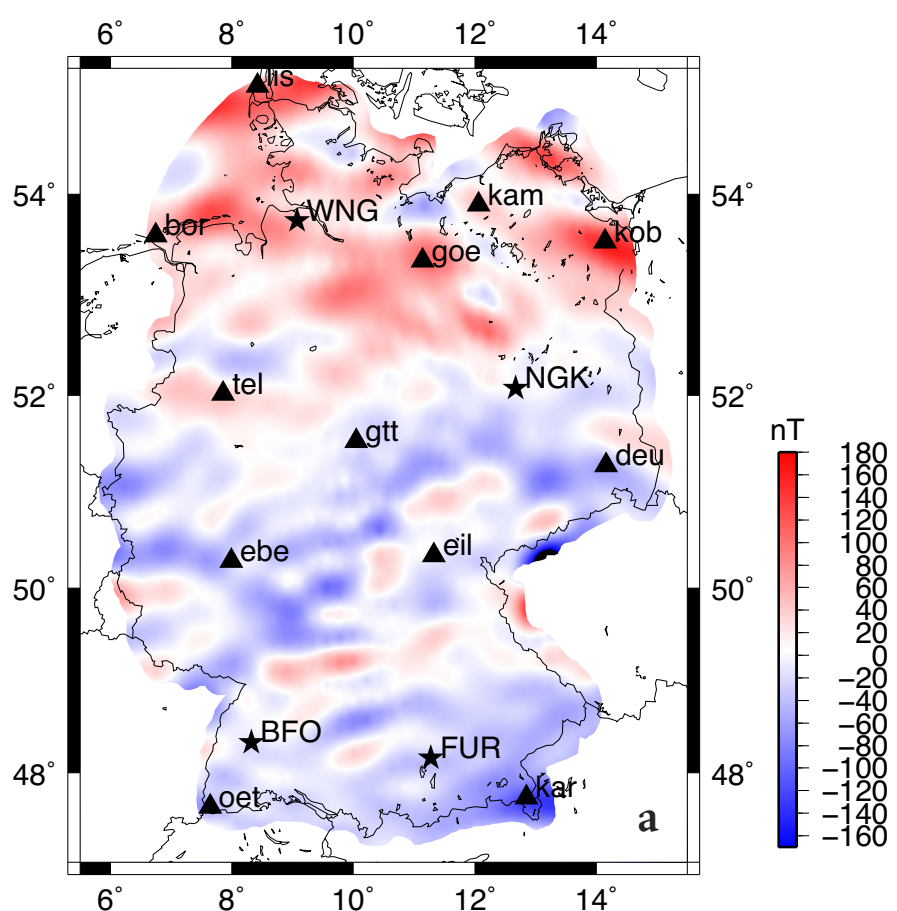

We considered both the $C_{Q N}$ and $C_{A M}$ results in our study. In most cases the quiet night time reduction could be done for times of $\mathrm{K}$ index 0 to 2 . Only in four cases (stations kar in 2003, kob and oet in 2006 and lis in 2010) was the K index 3 or higher for the whole time of variometer operation and the averaging was done over the whole time of operation in two of these cases ( 2 and 3 days for stations kob and kar, respectively). A table with the quiet night time values and related information for all stations is given as supplemental material. The annual mean data are available at the World Data Center Edinburgh at http:/ / www.wdc.bgs.ac.uk/.

From observatory annual means it is well known that external field variation and their induced counterparts do not average out completely, and that e.g. the solar cycle is clearly reflected in these values [Courtillot and Le Mouël 1976, Schmucker 1991, Verbanac et al. 2007]. Repeat station data reduced by Equation 2 will therefore be affected similarly. This remaining annually averaged external variation signal is indeed quite homogeneous over regions the size of Germany and can reasonably be estimated empirically from the three or four (BFO only operates since 2004) German observatories [Korte and Thébault 2007]. This is done by first subtracting core field annual mean predictions by a global model (see next section) from the observatory annual means time series. Then the lithospheric observatory bias is estimated as the average of the residuals at each observatory and for each component and also subtracted. The remaining time series of residual variations over the time interval 2000.5 to 2010.5 from the three observatories are averaged to obtain an empirical time series of external variations for each field component. A third data set of repeat station annual means, empirically corrected for external field influences by subtracting the averaged observatory
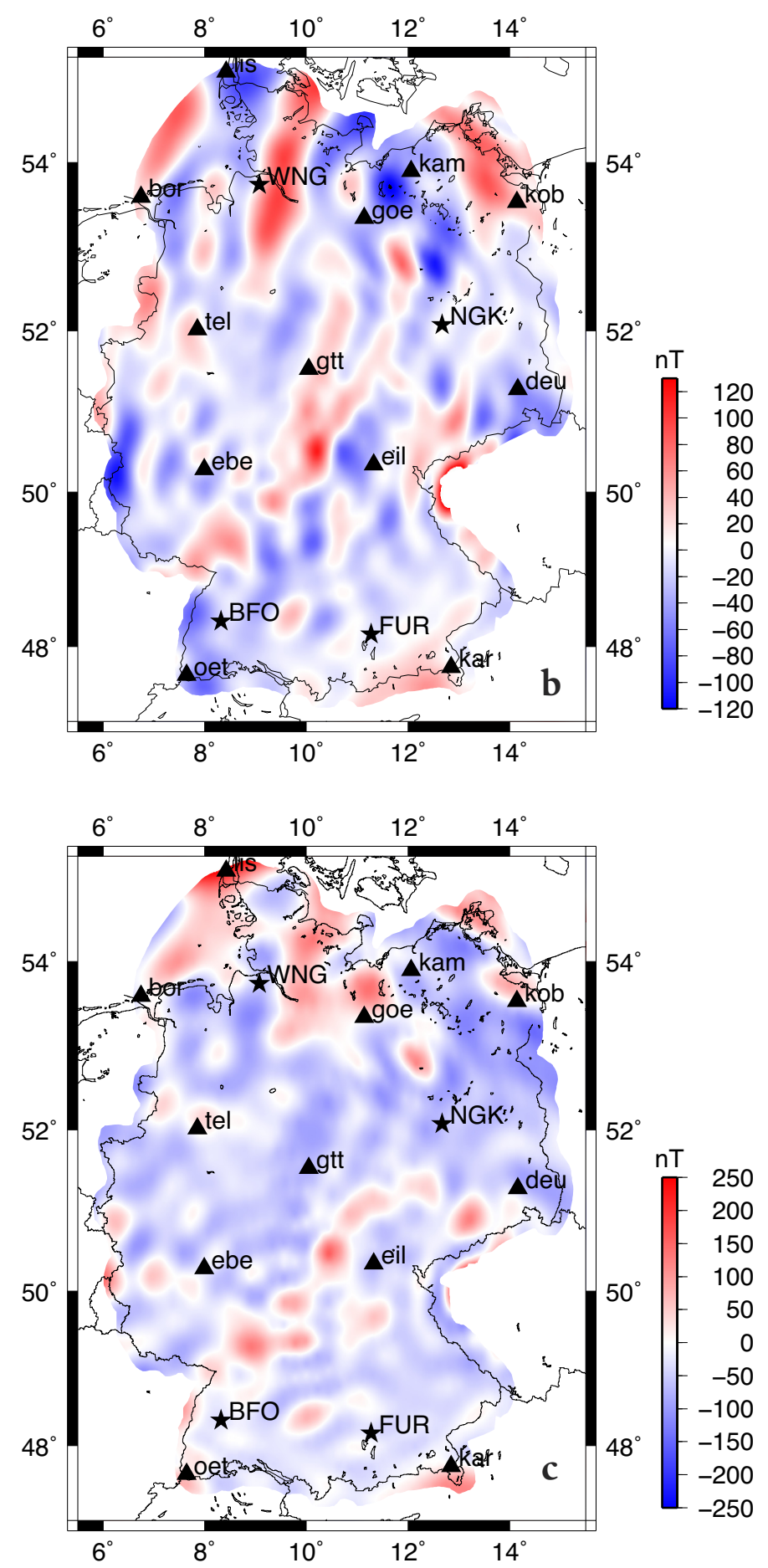

Figure 1. Magnetic observatories (stars) and first order repeat stations (triangles) in Germany, shown on the lithospheric magnetic anomaly maps for a) the North (X), b) the East (Y) and c) the vertical component (Z) obtained from the regional model by Korte and Thébault [2007].

residuals templates, is included in our study. Table 1 summarizes the different data types used here.

\section{The GRIMM-3 model and the German vector magnetic anomaly model}

Since modern magnetic field satellite data became available from 1999 on from the Ørsted and soon after also the CHAMP satellite, a number of new global magnetic field models have been developed. One of the most recent ones, 


\begin{tabular}{ll}
\hline Name & short description \\
\hline repeat station data & \\
$C_{Q N}$ & $C$ component reduced to quiet night time \\
$C_{A M}$ & $C$ component annual mean \\
$C_{E C}$ & $C$ comp. annual mean with empirical external field correction \\
model predictions & \\
$M C_{C}$ & $C$ component GRIMM3 core field prediction \\
$M C_{A M C}$ & $C$ component GRIMM3 core field "annual mean" \\
$M C_{C E}$ & $C$ comp. GRIMM3 core plus external field prediction \\
$C$ rustal bias estimates & \\
$C B$ & $C$ comp. crustal bias from German R-SCHA model \\
$C B_{Q N}$ & time averaged $C_{Q N}-M C_{C}$ \\
$C B_{A M}$ & time averaged $C_{A M}{ }^{-M C_{A M C}}$ \\
$C B_{Q N E}$ & time averaged $C_{Q N}-M C_{C E}$ \\
$C B_{A M E}$ & time averaged $C_{E C}-M C_{A M C}$ \\
\hline
\end{tabular}

Table 1. Summary of data, model predictions and results terminology.

taking advantage of the complete CHAMP data series from January 2001 to September 2010, is the third version of the GFZ Reference Internal Magnetic Model (GRIMM3). Here, we use the preliminary model as presented by Lesur et al. [2011], which also uses global observatory hourly means from 01 January 2001 to 31 December 2009. Some data selection for magnetically quiet times has been applied for all data types. Repeat station data have not been used, so that we can compare a truly independent data set here. The model in general follows the modeling approach for earlier GRIMM versions [Lesur et al. 2010] and will be described in detail by work in preparation by V. Lesur and co-workers. In the following, we only summarize the aspects which are important for this study.

The core field model is based on a spherical harmonic expansion up to degree and order 18 for the core field with the temporal continuity given by order $6 \mathrm{~B}$-splines with a knot-point spacing of six months. In order to avoid crustal field influence and include only the robustly described secular variation we limit the core field predictions to maximum degree and order 14. For comparison to the quiet night time component data $C_{\mathrm{QN}}$ we calculated core field model predictions $M C_{C}$ for the center of the time interval over which the night time data were averaged. The secular variation might vary non-linearly over time intervals of a year. Therefore 'annual mean' core field model predictions $M C_{A M}$ were obtained by averaging over 10 evenly distributed values within a calendar year for the comparison to the annual mean repeat station and observatory data centered on the middle of a year.

The lithospheric field is included by constant spherical harmonic degrees 19 to 60 in the GRIMM3 model. Due to the satellite altitude this part can only contain magnetic anomalies larger than a few $100 \mathrm{~km}$ wavelength. This global lithospheric field estimation describes only a small part of the local crustal bias at a repeat station. We could confirm this for the stations used in our study and we didn't consider the lithospheric field description of this model any further.

Although the main purpose of GRIMM3 is to provide a highly accurate description of the core field and its temporal evolution, the model contains some external field estimates as a by-product from the necessary separation of sources in the modeling approach. The external field description is limited to spherical harmonic degree 1. It contains a slowly evolving part, with a 100 days baseline, that is essentially similar to the parameterization used by Lühr and Maus [2010]. A rapidly evolving part is based on processed satellite data averaged by orbits, where again the baseline is 100 days. We determined GRIMM3 predictions $M C_{C E}$ with the external field description included for the centers of the time intervals over which the quiet night time repeat station data $C_{\mathrm{QN}}$ were averaged. This should give a good estimate for the majority of the data, which have been reduced to quiet night times with very low magnetic activity. A test showed that during night times of magnetic activity index $\mathrm{K}=0$ to 1 the external field model prediction over a few hours varies only by about $1 \mathrm{nT}$, and for $\mathrm{K}=2$ up to about $5 \mathrm{nT}$. The model prediction abbreviations we use are included in Table 1.

Crustal bias estimates for all German repeat stations have previously been obtained from a regional lithospheric vector anomaly model [Korte and Thébault 2007], which is shown in Figure 1. This model combines the lithospheric field information from the CHAMP satellite data, from an aeromagnetic grid and from the repeat stations using the technique of revised spherical cap harmonic analysis, R-SCHA [Thébault et al. 2006]. The repeat station crustal biases, $C B$, as determined in that investigation for each component $C$, are used for comparison in this study. 

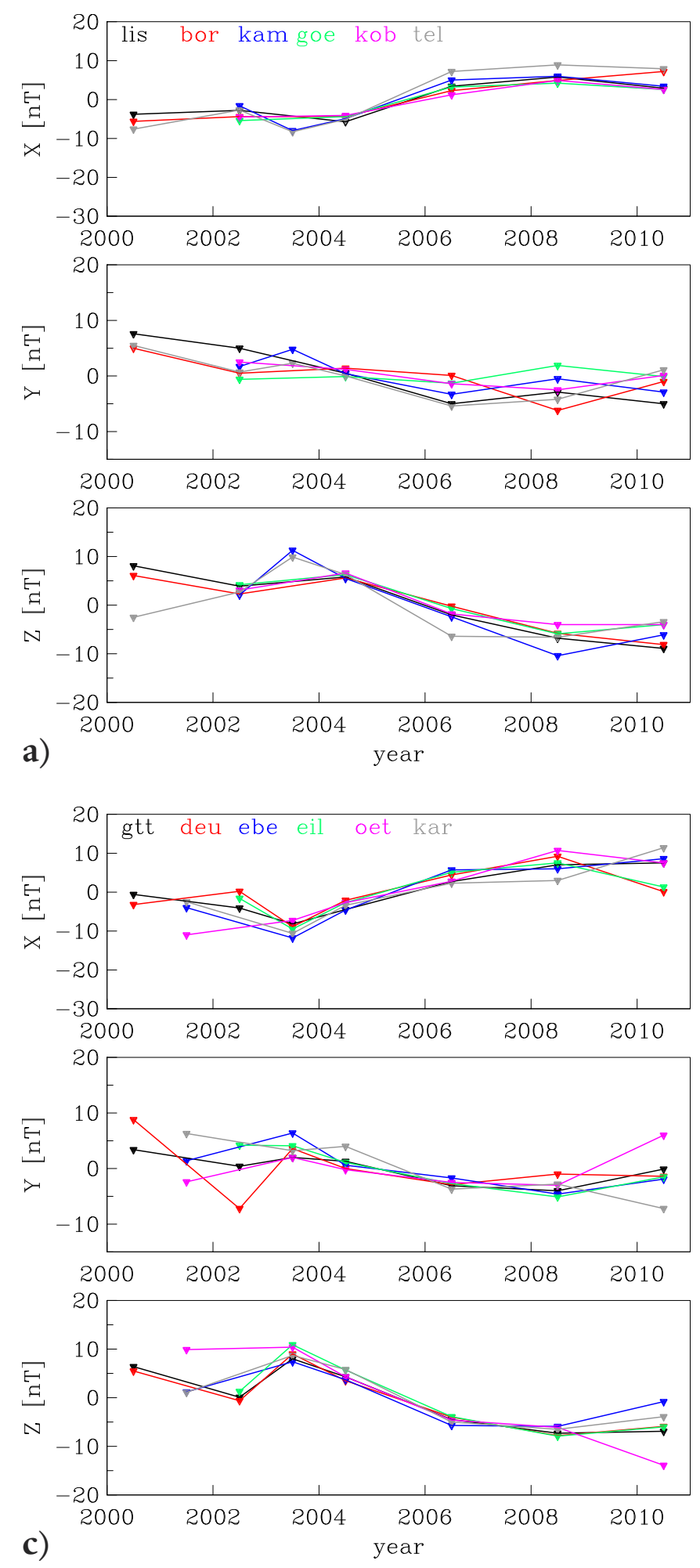
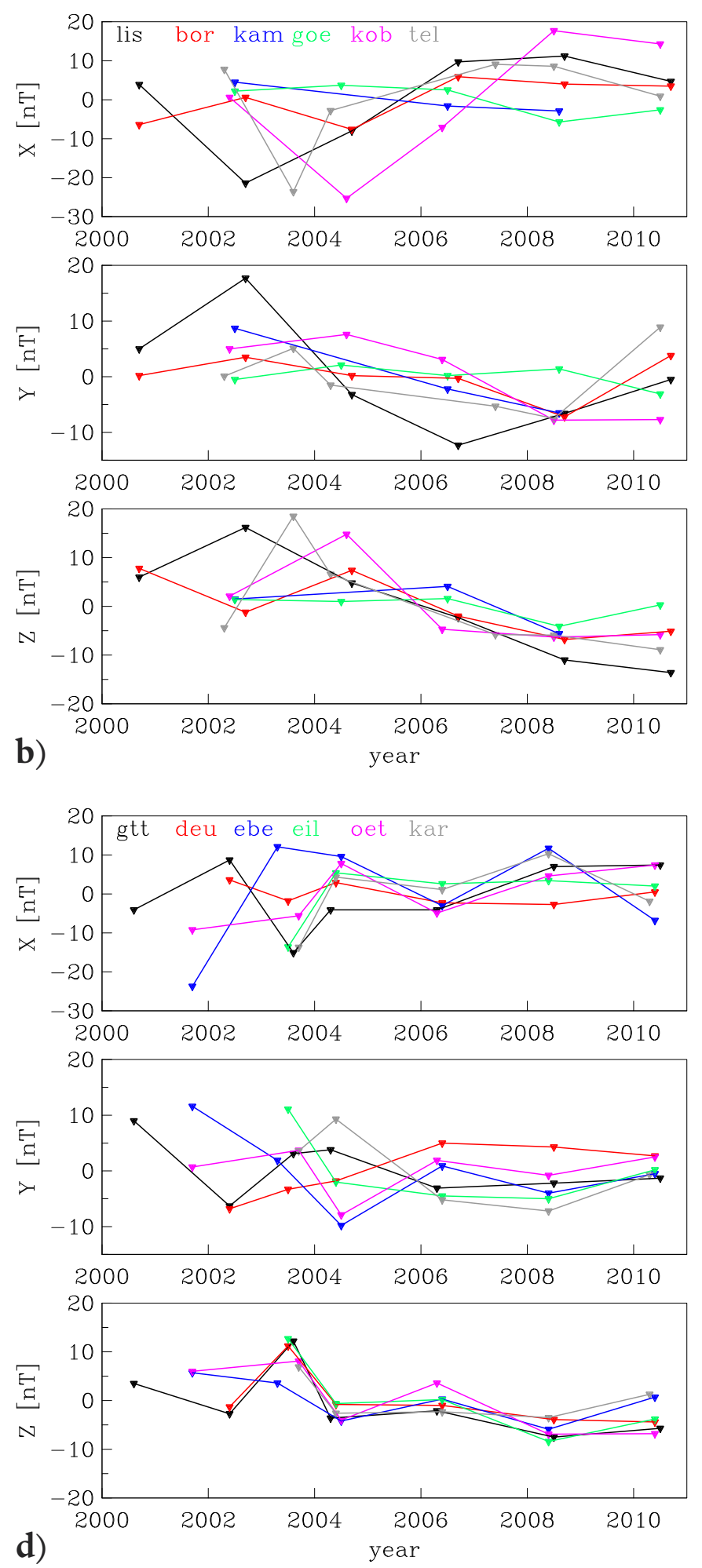

Figure 2. Repeat station data after subtraction of GRIMM3 core field predictions and constant average for North (X), East (Y) and vertical (Z) component. The left panels (a and c) show the annual mean results, the right panels (b and d) the quiet night time results. For better visibility the panels have been split up in northern ( $\mathrm{a}$ and $\mathrm{b}$ ) and southern ( $\mathrm{c}$ and $\mathrm{d})$ stations.

\section{Secular variation comparison and crustal biases}

First, we subtracted the core field predictions from the repeat station data, i.e. determined $C_{O N}-M C_{C}$ and $C_{A M}-M C_{A M C}$, and then determined the average value and standard deviation for each of these time series. The time averaged values are considered as crustal bias estimates, $C B_{Q N}$ and $C B_{A M}$. The standard deviations of $C B_{Q N}$ and $C B_{A M}$ contain the remain- ing signal and noise in the repeat station measurements that is not described by the core field and secular variation of the model. The time series with the average values subtracted are shown in Figure 2 and the average standard deviations for each component are tabulated in Table 2. The standard deviations of the $C B_{A M}$ are smaller than those of the $C B_{Q N}$ in all components on average. In the annual mean results large 


\begin{tabular}{lcccc}
\hline Crustal bias estimate & sd X $[\mathbf{n T}]$ & sd Y [nT] & sd Z [nT] & sd F [nT] \\
\hline$C B_{Q N}$ & 8.8 & 6.0 & 6.7 & 4.5 \\
$C B_{A M}$ & 6.1 & 3.6 & 6.5 & 4.0 \\
$C B_{Q N E}$ & 4.6 & 4.7 & 6.1 & 5.6 \\
$C B_{A M E}$ & 2.4 & 2.6 & 2.0 & 2.4 \\
\hline
\end{tabular}

Table 2. Average standard deviations of the crustal bias estimates.

scale variations common to all the repeat stations are very obvious, while there are some common trends, but also larger inhomogeneous variations, seen in the quiet night time results. The reduction to quiet night times does not reduce the external field influence in the data as much as one might have anticipated.

Next, external field contributions are taken into account for the same analysis. For the annual mean data, the model core field predictions are the same as before, but they are subtracted from the empirically corrected data: $C_{E C}-M C_{A M C}$. For the quiet night times, the data are the same as before, but the model predictions include all external contributions described by the model: $C_{\mathrm{QN}}-M C_{C E}$. The obtained time series are shown in Figure 3, the corresponding time averaged crustal bias estimates are named $C B_{A M E}$ and and their averaged standard deviations for each component are included in Table 2. As expected, the average standard deviations are lower now, except for quiet night time total intensity (F) results. For the annual mean data, they are no higher than 2 to $3 \mathrm{nT}$ on average and thus lie in the order expected for measurement uncertainties for repeat station data. They are somewhat higher for the quiet night time data, indicating remains of external field contributions in the results and slightly higher than the fit of the GRIMM3 model to the magnetic observatory hourly mean data used in the model.

In general, the horizontal components $\mathrm{X}$ and $\mathrm{Y}$ are more sensitive to direct changes in ionospheric and magnetospheric magnetic fields, while the vertical component $Z$ and consequently also $\mathrm{F}$ are strongly influenced by the induced secondary fields, which can vary more locally. The fact that the average scatter now is highest in $\mathrm{Z}$ and $\mathrm{F}$ for the quiet night time results indicates that, perhaps not surprisingly, the description of the external fields themselves is more accurate than the contribution from their induced counterparts in the GRIMM3 model. The scatter in Z (and F) of station kob is particularly high (see Figure 3), and in fact the data for 2006 could not be obtained for truly quiet times, but instead was averaged over two days with magnetic activity index at Niemegk not lower than $\mathrm{K}=4$. It is not surprising that the model predictions determined for only one point in time within this interval does not fit well in this case. However, this is the only example where we noticed an obvious correlation between an outlier in the residuals, and stronger than average magnetic activity during data acquisition. Other ap- parent outliers, e.g. for station lis in 2003 or station ebe in 2001 are not correlated to high magnetic activity. Also, the other way round, data reduced to night times with activity index $\mathrm{K}=3$, e.g. $\mathrm{kar}$ in 2003 or lis in 2010 are not clearly linked to outliers in the model comparison results.

Both the empirical correction for external influences and the external field contributions described by the model succeed in reducing the undesired signal from outside the Earth and their induced counterparts. Comparing Figure 2 and Figure 3, it becomes clear that apparent long-term trends (increase in $\mathrm{X}$ residuals and decrease in $\mathrm{Z}$ residuals in Figure $2 \mathrm{a}$ and c) are not due to an insufficient secular variation description in GRIMM3, but are caused by external field contributions in the data. Moreover, the deviations seen in Figure 2 around 2003 might seem to suggest that we see some signal of the geomagnetic jerk, a an abrupt change of secular acceleration originating in the core that happened around that time (see Mandea et al. [2010] for a recent review on geomagnetic jerks), in the repeat station data, but not adequately described by the GRIMM3 model. However, it becomes clear from Figure 3 that this signal is captured and described as being of external origin by the global model.

We now turn to a comparison of the crustal bias estimates obtained as averages of the residuals between the different data and models, listed in Tables 3 and 4 . None of the repeat stations lie on particularly strong lithospheric anomalies. The largest crustal bias estimates are in the order of $150 \mathrm{nT}$, and at many locations they only reach several tens of $\mathrm{nT}$. The estimates in general agree within approximately $10 \mathrm{nT}$ in $\mathrm{Y}$ and $\mathrm{F}$ and within $20 \mathrm{nT}$ in $\mathrm{X}$ and $\mathrm{Z}$. The estimates from the annual mean data with and without external field correction agree very closely in all components, due to the way they are determined and despite the removal of trends by the empirical external field correction. The rather large differences between the crustal bias estimates obtained from the quiet night time data with $\left(\mathrm{CB}_{\mathrm{QNE}}\right)$ and without $\left(\mathrm{CB}_{\mathrm{QN}}\right)$ consideration of the external field contributions included in GRIMM3 suggests systematic, long term contributions from the ionospheric and magnetospheric fields in the repeat station data reduced to quiet night times, probably particularly from the ring current. Therefore, the estimates probably give the most accurate amplitudes of the lithospheric signal. The new crustal bias estimates are in reasonable agreement with the previous results from the German vector lithospheric 

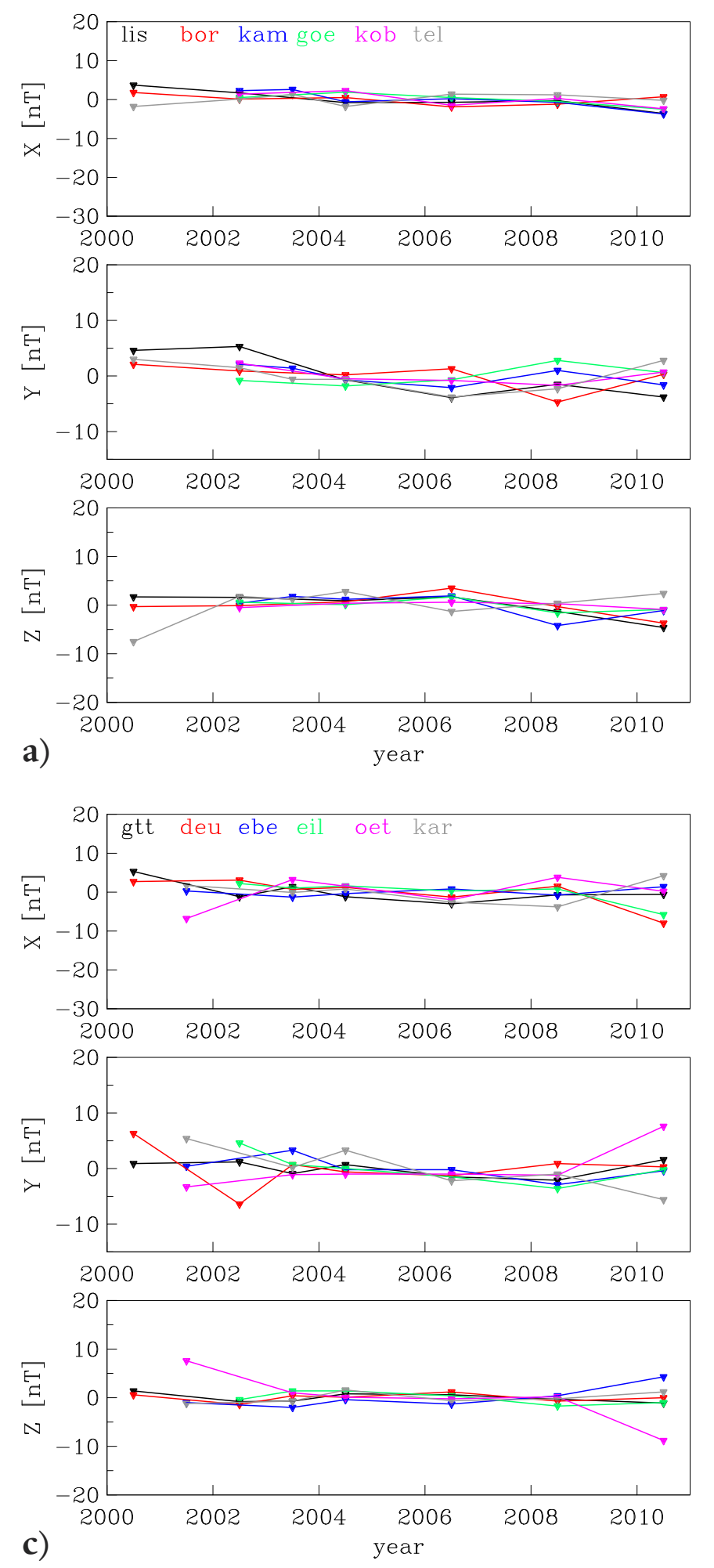
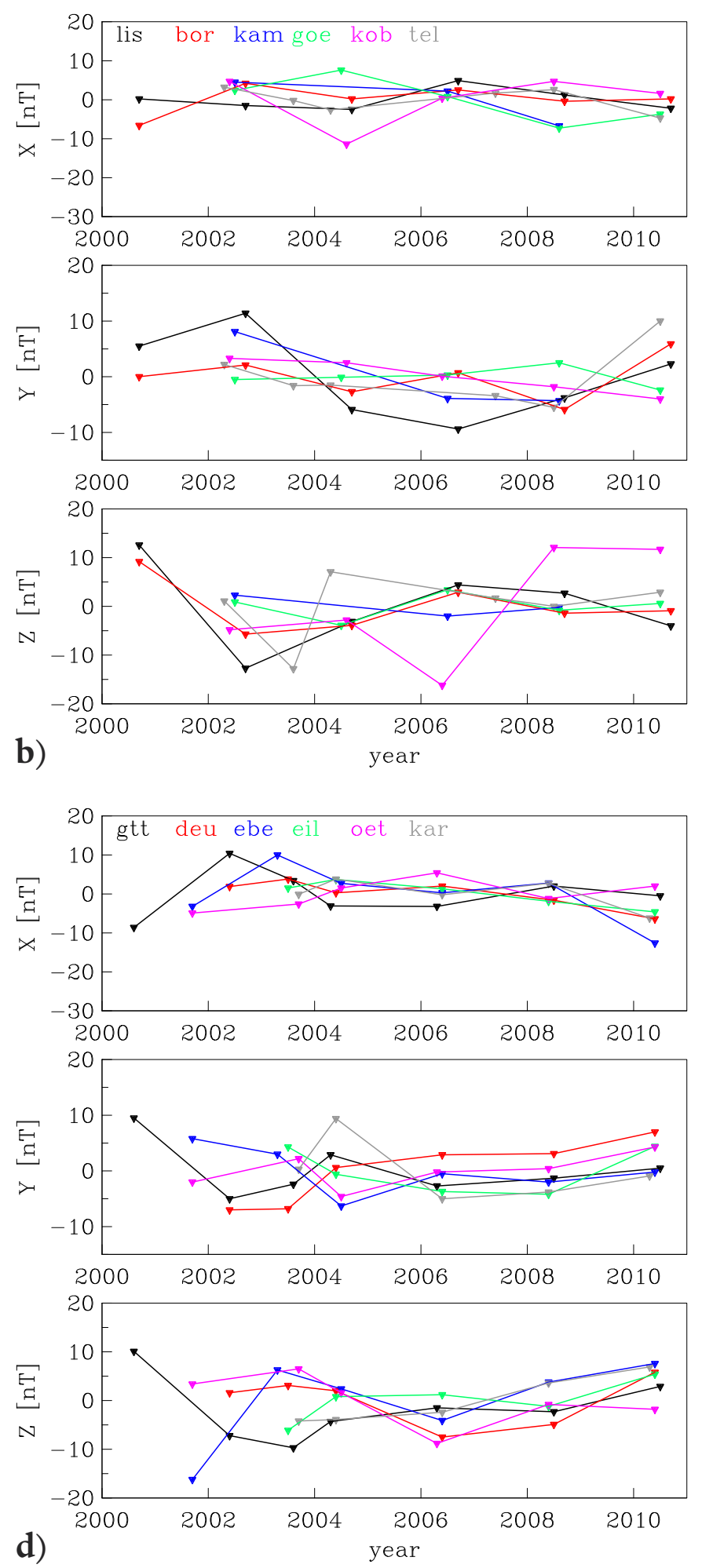

Figure 3. Repeat station data after subtraction of GRIMM3 core field predictions, a constant average for North (X), East (Y) and vertical (Z) component, and removal of external field influences. The left panels (a and c) show the annual means with the empirical external field correction. The right panels (b and d) show the quiet night time results where the GRIMM3 external field description has been used (see text for details). For better visibility the panels have been split up in northern ( $\mathrm{a}$ and $\mathrm{b}$ ) and southern ( $\mathrm{c}$ and $\mathrm{d})$ stations.

anomaly model. The way these were determined also does not provide information about systematic long term contributions from external fields.

Finally, we investigated whether the time series of residuals after subtraction of core and external field estimates from the repeat station data show any remaining long-term trends, which might e.g. indicate induced lithospheric anomalies. We performed linear regressions of the $C_{E C}-M C_{A M C}$ time series (Figure $3 \mathrm{a}$ and $\mathrm{c}$ ), i.e. the time series where the removal of core and external field signals has been most successful. Note that with barely 10 years of data, and with only 4 to 7 data points available in each time series this analysis 
KORTE AND LESUR

\begin{tabular}{|c|c|c|c|c|c|c|c|c|c|c|}
\hline Station & $X B$ & $X B_{Q N}$ & $X B_{A M}$ & $X B_{Q N E}$ & $X B_{A M E}$ & $Y B$ & $Y B_{Q N}$ & $Y B_{A M}$ & $Y B_{Q N E}$ & $Y B_{A M E}$ \\
\hline lis & 100.46 & 108.32 & 102.67 & 118.32 & 102.44 & -87.65 & -90.48 & -91.57 & -93.28 & -91.31 \\
\hline bor & -13.1 & 0.6 & -8.9 & 7.12 & -9.13 & 30.35 & 28.23 & 29.45 & 26.15 & 29.71 \\
\hline $\mathrm{kam}$ & 6.55 & 23.1 & 8.18 & 27.7 & 8.58 & -60.12 & -55.2 & -57.97 & -57.63 & -57.78 \\
\hline goe & 66.29 & 86.42 & 70.64 & 88.86 & 68.93 & -16.31 & -27.68 & -24.94 & -28.94 & -24.09 \\
\hline kob & 102.6 & 109.94 & 106.92 & 124 & 105.21 & 33.37 & 34.24 & 32.88 & 29.42 & 33.73 \\
\hline tel & 16.88 & 30.75 & 21.64 & 41.2 & 23.01 & 21.67 & 24.77 & 20.7 & 20.73 & 20.47 \\
\hline $\mathrm{gtt}$ & -30.95 & -29.18 & -38.13 & -19.63 & -36.76 & 18.12 & 26.05 & 26.79 & 22.88 & 26.55 \\
\hline deu & -88.27 & -77.17 & -89.84 & -67.5 & -88.47 & -59.62 & -64.25 & -59.21 & -66.93 & -59.45 \\
\hline ebe & -36.1 & -26.32 & -35.42 & -17.9 & -34.93 & -35.58 & -40.08 & -39.17 & -42.73 & -39.26 \\
\hline eil & -37.33 & -21.54 & -33.88 & -12 & -33.48 & -15.95 & -19.94 & -17.18 & -22.36 & -17 \\
\hline oet & -5.78 & 13.72 & 0.25 & 21.23 & 0.73 & -33.95 & -32.45 & -28.82 & -34.58 & -28.91 \\
\hline kar & -65.43 & -56.78 & -67.07 & -48.7 & -66.58 & 24.55 & 16.96 & 19.57 & 15.1 & 19.48 \\
\hline
\end{tabular}

Table 3. Crustal bias estimates for $\mathrm{X}$ and $\mathrm{Y}$ component in $\mathrm{nT}$.

\begin{tabular}{|c|c|c|c|c|c|c|c|c|c|c|}
\hline Station & $Z B$ & $Z B_{Q N}$ & $Z B_{A M}$ & $Z B_{Q N E}$ & $Z B_{A M E}$ & $F B$ & $F B_{Q N}$ & $F B_{A M}$ & $F B_{Q N E}$ & $F B_{A M E}$ \\
\hline lis & 136.55 & 129.02 & 128.62 & 113.08 & 128.96 & -- & 158.68 & 156.37 & 147.29 & 156.56 \\
\hline bor & 3.35 & -3.38 & -1.75 & -13.87 & -1.41 & -- & -2.94 & -4.95 & -10.27 & -4.77 \\
\hline kam & -85.51 & -78.4 & -71.4 & -87.97 & -71.68 & -- & -65.28 & -64.18 & -72.54 & -64.31 \\
\hline goe & -30.68 & -40.06 & -36.22 & -47.66 & -34.6 & -- & -5.52 & -7.78 & -11.67 & -7.05 \\
\hline kob & -113.15 & -118.28 & -119.42 & -143.1 & -117.8 & -- & -69.24 & -71.42 & -87.29 & -70.69 \\
\hline tel & -27.17 & -21.88 & -21.2 & -38.5 & -22.31 & -- & -8.14 & -11.11 & -19.42 & -11.6 \\
\hline $\mathrm{gtt}$ & -54.18 & -49.17 & -49.39 & -65.01 & -50.5 & -- & -56.49 & -60.16 & -67.33 & -60.69 \\
\hline deu & 12.23 & 7.77 & 9.66 & -9.08 & 8.55 & -- & -24.07 & -27.24 & -35.83 & -27.75 \\
\hline ebe & -23.83 & -24.87 & -22.02 & -38.33 & -22.42 & -- & -33.63 & -34.75 & -42.46 & -34.99 \\
\hline eil & -43.3 & -44.98 & -44.48 & -60.78 & -44.77 & -- & -50.08 & -54.63 & -60.67 & -54.78 \\
\hline oet & 58.81 & 52.1 & 54.6 & 39.92 & 54.2 & -- & 52.6 & 48.82 & 45.06 & 48.57 \\
\hline kar & 107.02 & 104.46 & 107.13 & 92.8 & 106.73 & -- & 69.12 & 66.99 & 62.18 & 66.76 \\
\hline
\end{tabular}

Table 4. Crustal bias estimates for $Z$ and $F$ component in $n T$.

\begin{tabular}{|c|c|c|c|}
\hline Station & $X_{E C^{-}}-X_{A M C}$ & $Y_{E C^{-M}} Y_{A M C}$ & $Z_{E C^{-M Z}} Z_{A M C}$ \\
\hline lis & -0.61 & -0.94 & -0.56 \\
\hline bor & -0.17 & -0.35 & -0.21 \\
\hline kam & -0.67 & -0.33 & -0.47 \\
\hline goe & -0.42 & 0.37 & -0.24 \\
\hline kob & -0.48 & -0.22 & -0.05 \\
\hline tel & 0.16 & -0.20 & -0.53 \\
\hline$g t t$ & -0.44 & -0.09 & -0.13 \\
\hline deu & -0.85 & -0.14 & -0.01 \\
\hline ebe & 0.13 & -0.34 & 0.54 \\
\hline eil & -0.77 & -0.60 & -0.27 \\
\hline oet & 0.54 & 0.90 & -1.37 \\
\hline kar & 0.01 & -1.06 & 0.17 \\
\hline
\end{tabular}

Table 5. Linear trends in $\mathrm{nT} / \mathrm{yr}$ obtained for the different component residual time series. 


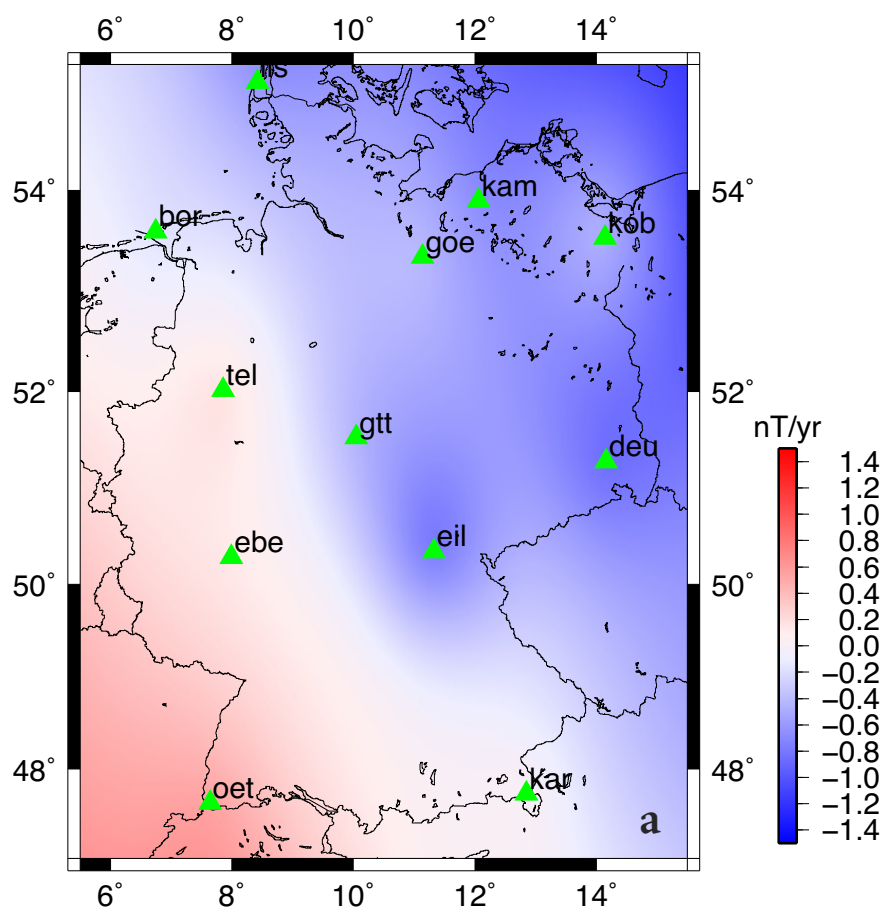

cannot be considered very robust. Table 5 lists the linear trends obtained by the regression. For a couple of stations trends in the order of 0.5 to $1 \mathrm{nT} / \mathrm{yr}$ are detected. To get an idea of the spatial distribution of these results we visualized them in Figure 4 by a simple interpolation of the trends. The maps are meant only to give an idea of the distribution of stations where positive or negative trends were detected and to facilitate an easy comparison. If any of the detected trends are real, they might be much more localized around smallscale anomalies. The comparison of Figure 4 to Figure 1 and of the numbers in Table 5 to Table 3 and 4 does not indicate any correlations between locations on strong crustal anomalies and detected trends. For several of the stations, we get similar results as carried out two years ago with data only up to 2008.5 and an earlier version of the GRIMM model. However, it seems premature to interpret any of these trends as a magnetic field signal unless the robustness of these results can be confirmed by longer or denser time series.

\section{Discussion and conclusions}

We have compared the most recent GRIMM magnetic field model (preliminary GRIMM3) with German repeat station data in order to investigate the accuracy of the data and the model and to evaluate the benefits of repeat station data in areas comparatively densely covered by magnetic observatories. The repeat station data form an independent data set and have not been used to derive the GRIMM3 model.

The subtraction of GRIMM3 core field predictions from the data has shown that significant external field contamination is present both in repeat station annual means and quiet night time data. Apparent long-term (years to decade) trends in repeat station data secular variation compared to core field and secular variation models can be due to external field con-
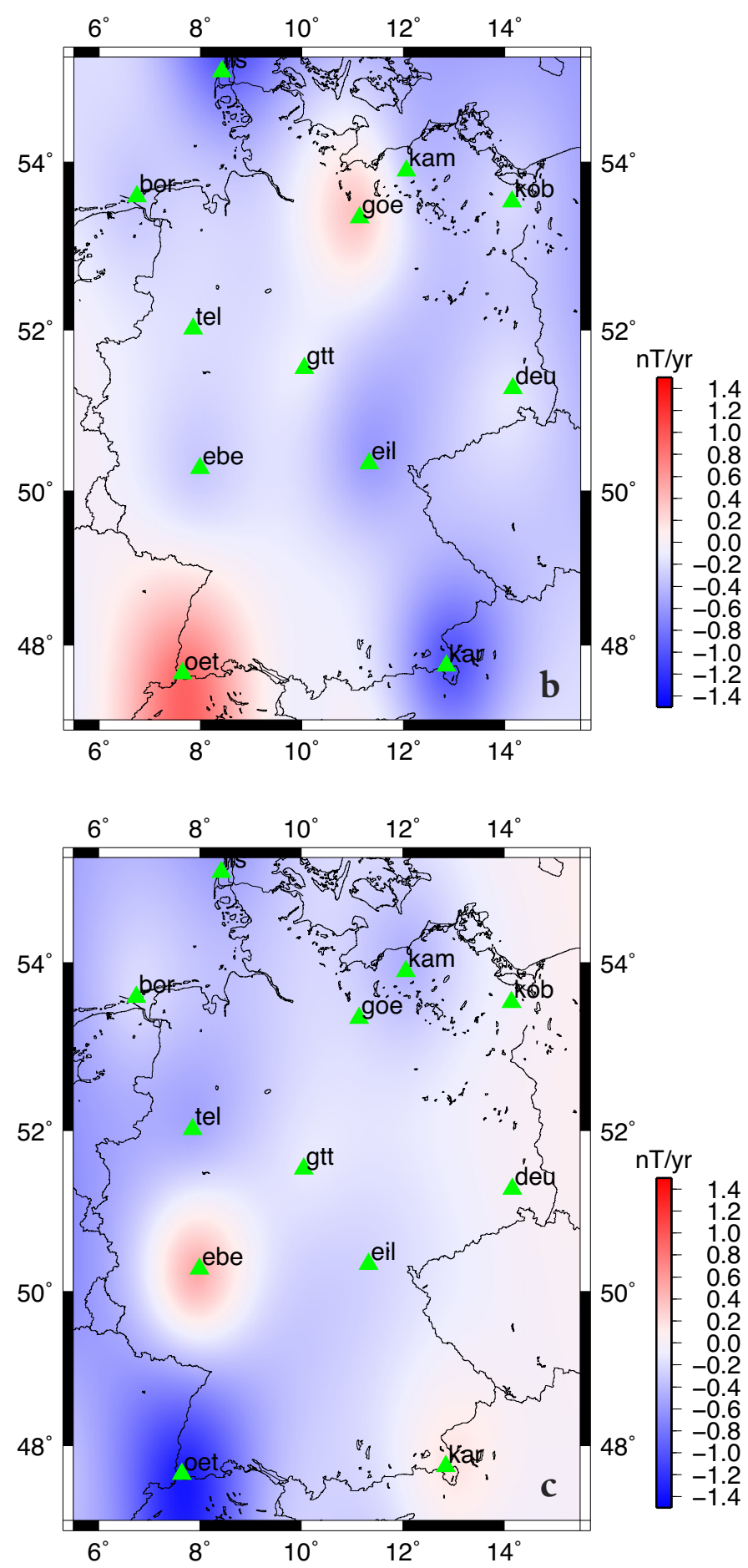

Figure 4. Visualization of repeat stations with negative and positive trends in crustal biases for a) the North (X), b) the East (Y) and c) the vertical ( $\mathrm{Z}$ ) component. Note that detected trends might not be significant and those that are might be much more localized than this figure suggests. See text for more details.

tributions in the data and do not necessarily hint at insufficient secular variation description in the model. In fact the comparison including the consideration of the external field description in the global model suggests that the core field secular variation for this area is described with an accuracy clearly better than $1 \mathrm{nT} / \mathrm{yr}$. The external field contamination in commonly used repeat station results might be small enough to be considered insignificant for general regional 
mapping of secular variation, but it certainly has to be considered if repeat station data shall be used for high resolution secular variation studies.

The optimal treatment to eliminate the external field influences that remain after the commonly used repeat station data processing, however, has yet to be found. For small regions, for which several good data series are available, an empirical approach to subtract the common signal from annual mean data series seems to work best. In our case the scatter in the residuals between corrected annual mean data and the core field model was reduced to the order expected as uncertainties in repeat station measurements. This method, however, does not give any information about long-term 'offsets' caused by external field contributions. The existence of such 'offsets' is suggested by clear differences between the time-averaged crustal bias values obtained by subtraction of the core field or core and external field model, respectively, from the quiet night time data. On the other hand, the residuals between quiet night time data and GRIMM3 core and external field description show the largest scatter and thus clearly still contain remains of high frequency ionospheric and magnetospheric field contributions, at least as long as the measurements cannot be reduced to extremely quiet conditions. Consequently, in order to determine the core field secular variation signal from repeat station data, the empirical approach seems more successful, while to determine the lithospheric anomaly value (crustal bias) at a station, the subtraction of a model such as GRIMM3, which includes as much as possible external field description, seems advisable if the data were taken at truly quiet times or enough data to determine a statistical average for a location are available.

An analysis of long-term trends in the residual repeat station data after the subtraction of core and external field influences indicates that some small remaining time-varying magnetic signal, probably related to induced lithospheric anomalies, could exist at some locations, but considering the expected size of such a signal and the measurement uncertainties it seems premature to interpret the observed trends. More data points from each location are necessary to carry out such an analysis in a more robust way. If a continuous, homogeneous global field model for the past decades up to present times becomes available we will be able to include the previous ground vector survey results from the same stations.

As a final remark we would like to point out that this study focused on a region of the world that is characterized by a dense network of continuously recording magnetic observatories. It is not clear if global models describe the secular variation equally well in regions where much less high quality ground data time series are available and a comparative study, e.g. for South Africa where both a good repeat station network and strong core field variations and gradient exist, could be instructive.
Acknowledgements. We thank Martin Fredow and Manfred Schüler for performing the bi-annual repeat station measurements and processing the raw data. The work presented in this paper includes data obtained at the magnetic observatory Fürstenfeldbruck and Black Forest Observatory. We thank the Ludwig Maximilians University Munich and the Universities of Karlsruhe and Stuttgart for operating these observatories respectively. The GRIMM-3 model relies on global observatory data, and we thank all the national institutes that support them and INTERMAGNET for promoting high standards of magnetic observatory practice and global data availability (www.intermagnet.org). The CHAMP mission was sponsored by the Space Agency of the German Aerospace Center (DLR) through funds of the Federal Ministry of Economics and Technology (grant code 50EE0944). We also thank the CHAMP data processing team. Plots were made using the Generic Mapping Tools [www.soest.hawaii. edu/gmt; Wessel and Smith 1998]. We acknowlegde constructive comments from two anonymous reviewers.

\section{References}

Alldredge, L.R. (1983). Varying geomagnetic anomalies and secular variation, J. Geophys. Res., 88, 9443-9451.

Courtillot, V., and J.-L. Le Mouël (1976). On the long-period variations of the Earth's magnetic field from 2 months to 20 years, J. Geophys. Res., 81, 2941-2950.

Hemant, K., and S. Maus (2005). Geological modeling of the new CHAMP magnetic anomaly maps using a geographical information system technique, J. Geophys. Res., 110, B12103; doi:10.1029/2005JB003837.

Hulot, G., N. Olsen, E. Thébault and K. Hemant (2009). Crustal concealing of small-scale core-field secular variation, Geophys. J. Int., 177, 361-366.

Jackson, A. (2007). Studies of crustal magnetic anomalies of the British Isles, Astronomy and Geophysics, 48 (2), 8-13.

Korte, M., and M. Fredow (2001). Magnetic repeat station survey of Germany 1999/2000, Scientific Technical Report, Potsdam STR01 / 04, 1-23.

Korte, M., and M. Mandea (2003). Improvements planned for European geomagnetic repeat stations, EOS Trans., Amer. Geophys. Soc., 84, 160.

Korte, M., and E. Thébault (2007). Geomagnetic repeat station crustal biases and vectorial anomaly maps for Germany, Geophys. J. Int., 170, 81-92.

Lesur, V., and D. Gubbins (2000). Using geomagnetic secular variation to separate remanent and induced sources of the crustal magnetic field, Geophys. J. Int., 142, 889-897.

Lesur, V., I. Wardinski, M. Hamoudi and M. Rother (2010). The second generation of the GFZ Reference Internal Magnetic Model: GRIMM-2, Earth Planets Space, 62, 765773.

Lesur, V., I. Wardinski and M. Hamoudi (2011). Third version of the GFZ Reference Internal Magnetic Model: GRIMM-3, Abstract, 25 ${ }^{\text {th }}$ IUGG General Assembly (Melbourne).

Lühr, H., and S. Maus (2010). Solar cycle dependence of quiet-time magnetospheric currents and a model of their near-Earth magnetic fields, Earth Planets Space, 62, 843848.

Macmillan, S., and A. Thomson (2003). An examination of 
observatory biases during the Magsat and Ørsted missions, Phys. Earth Planet. Int., 135, 97-105.

Mandea, M., R. Holme, A. Pais, K. Pinheiro, A. Jackson and G. Verbanac (2010). Geomagnetic jerks: rapid core field variations and core dynamics, Space Sci. Rev., 155, 147175.

McLeod, M.G. (1996). Spatial and temporal power spectra of the geomagnetic field, J. Geophys. Res., 101, 2745-2763.

Mundt, W., and G. Porstendorfer (1977). Zusammenhänge zwischen Analysen der Magnetotellurik und der magnetischen Säkularvariation im Hinblick auf eine Leitfähigkeitsanomalie im oberen Erdmantel Mitteleuropas, Gerlands Beitr. Geophys., 86, 337.

Mundt, W. (1978). Geomagnetic secular variation anomalies in GDR, J. Geomag. Geoelectr., 30, 523-531.

Mundt, W., and G. Porstendorfer (1978). Mögliche Zusammenhänge zwischen einer elektrischen Leitfähigkeitsanomalie im Erdmantel und anomalen magnetischen Säkularvariationen in Mitteleuropa, Geodät. u. Geophys. Veröff. d. NKGG, 39, 153-162.

Mundt, W. (1981). Regionale und lokale Anomalien der geomagnetischen Säkularvariation in Mitteleuropa, Veröffentl. d. Zentralinst. f. Physik d. Erde, 70, 33-43.

Newitt, L.R., C.E. Barton and J. Bitterly (1996). Guide for magnetic repeat station surveys, International Association of Geomagnetism and Aeronomy.

Podsklan, J., V. Kuznetsova and V. Masimchuk (1993). Some peculiarities of the secular variation of the geomagnetic field in the Carpathians, Phys. Earth Planet. Int., 77, 137141.

Schmucker, U. (1991). Solar cycle variations and corrected annual means for external effects at Fürstenfeldbruck 1951-1968, In: M. Beblo and H. Soffel (eds.), 150 Years Earthmagnetic Observatories München - Maisach Fürstenfeldbruck, vol. 5, München, Münchner Geophysikalische Mitteilungen, pp. 217-248.

Spitta, P. (1991). Regional survey in the surroundings of Göttingen in search of anomalies of secular variations, Münchner Geophys. Mitt., 5, 159-174.

Thébault, E., J.J. Schott and M. Mandea (2006). Revised Spherical Cap Harmonic Analysis (R-SCHA): validation and properties, J. Geophys. Res., 111, B01102; doi: 10.1029/2005JB003836.

Thébault, E., K. Hemant, G. Hulot and N. Olsen (2009). On the geographical distribution of induced time-varying crustal magnetic fields, Geophys. Res. Lett., 36, L01307; doi:10.1029/2008GL036416.

Verbanac, G., M. Korte and M. Mandea (2007). On long-term trends of the European geomagnetic observatory biases, Earth Planets Space, 59 (7), 685-695.

Wessel, P., and W.H.F. Smith (1998). New, improved version of the Generic Mapping Tools released, Eos Trans. AGU, 79,579 .
${ }^{\star}$ Corresponding author: Monika Korte,

Helmholtz-Centre Potsdam, GFZ German Research Centre for Geosciences, Potsdam, Germany; email: monika@gfz-potsdam.de.

(C) 2012 by the Istituto Nazionale di Geofisica e Vulcanologia. All rights reserved. 